\title{
Erratum to: 'Screen-and-treat program by point-of-care of Atopobium vaginae and Gardnerella vaginalis in preventing preterm birth (AuTop trial): study protocol for a randomized controlled trial'
}

\author{
Florence Bretelle ${ }^{1,2}$, Florence Fenollar ${ }^{2}$, Karine Baumstarck ${ }^{3,4}$, Cécile Fortanier ${ }^{5}$, Jean François Cocallemen ${ }^{1}$, \\ Valérie Serazin ${ }^{6}$, Didier Raoult ${ }^{2}$, Pascal Auquier ${ }^{3,4}$, Sandrine Loubière ${ }^{3,4^{*}}$ and the Groupe de Recherche en \\ Obstétrique et Gynécologie (GROG)
}

After publication of this work [1], we noted that we failed to include the complete list of all coauthors. The full list of authors has now been updated. The Authors' contributions, Acknowledgements and Competing interests section have been modified accordingly. We are publishing this erratum to update the author list, which is as follows:

Florence Bretelle, Florence Fenollar, Karine Baumstarck, Cécile Fortanier, Jean François Cocallemen, Valérie Serazin, Didier Raoult, Pascal Auquier, Sandrine Loubière, and the Groupe de Recherche en Obstétrique et Gynécologie.

\section{Competing interests}

The authors declare that they have no competing interests.

\section{Authors' contributions}

$F B, C F, J F C, F F, V S, D R, K B, P A$ and SL conceived and/or designed the study, including the power calculation. CF and JFC acquired legal authorizations. The study protocol and manuscript have been drafted by FB, CF, SL, KB and PA. All authors read and approve the final manuscript.

\section{Acknowledgements \\ We would like to acknowledge the Groupe de Recherche en Obstétrique et Gynécologie (GROG), including Dr Hélène Heckenroth, Dr Raoul Desbriere Dr Nadia Slim Dr Nawal Chenni-Asselah Dr Xavier Danoy Dr Franck Mauviel Pr André Bongain Pr Pierre Mares Pr Patrick Rozenberg Dr Thomas Schmitz Pr Alexandra Benachi Pr Marie-Victoire Senat Pr Bassam Haddad Dr Jean-Pierre Ménard Pr Gilles Kayem Pr Loic Sentilhes Pr Céline Chauleur Dr Jean-Luc Volumenie Dr Philippe Kadhel Pr Florence Fenollar Pr Pascal Auquier}

Sandrine Loubière \& Cécile Fortanier Dr Karine Baumstarck Dr Nathalie Lesavre Dr Stéphane Honoré \& Dr Anita Cohen. This work is supported by institutional grants from the French 2013 Programme Hospitalier Recherche Clinique National. The sponsor was represented by Assistance Publique, Hôpitaux de Marseille, France; and its role was to control the appropriateness of ethical and legal considerations. The authors are grateful to all the investigators for their participation in the study. We thank Stéphane Honoré and Kahena Amichi.

\section{Author details}

'Department of Gynaecology and Obstetrics, Gynépole, Marseille, Pr Boubli, Hôpital Nord, Assistance Publique-Hôpitaux de Marseille, AMU, Aix- Marseille Université, Marseille, France. ${ }^{2}$ Aix-Marseille Université, Unité de Recherche sur les Maladies Infectieuses Tropicales et Emergentes, UM63, CNRS 7278, IRD 198, INSERM 1095, Marseille, France. ${ }^{3}$ EA3279 Self-perceived Health Assessment Research Unit and Department of Public Health, AP-HM, Aix-Marseille University, Marseille, France. ${ }^{4}$ Department of Research and Innovation, Support Unit for clinical research and economic evaluation, Assistance Publique - Hôpitaux de Marseille, Marseille 13385, France. ${ }^{5}$ Hôpital Sainte Marguerite, Assistance Publique - Hôpitaux de Marseille, Marseille cedex 9, France. ${ }^{6}$ Service de biologie médicale, CHI Poissy-Saint Germain, Poissy Cedex, France - EA 2493, UFR des sciences de la santé, 78180 Montigny-Le-Bretonneux, France.

Published online: 12 February 2016

\section{Reference}

. Florence B, Florence F, Karine B, Cécile F, Jean C, Valérie S, et al. Screen-andtreat program by point-of-care of Atopobium vaginae and Gardnerella vaginalis in preventing preterm birth (AuTop trial): study protocol for a randomized controlled trial. Trials. 2015;16:470.

\footnotetext{
* Correspondence: sandrine.loubiere@univ-amu.fr

${ }^{3}$ EA3279 Self-perceived Health Assessment Research Unit and Department of Public Health, AP-HM, Aix-Marseille University, Marseille, France

${ }^{4}$ Department of Research and Innovation, Support Unit for clinical research and economic evaluation, Assistance Publique - Hôpitaux de Marseille, Marseille 13385, France

Full list of author information is available at the end of the article
} 